\title{
Efficacy of a hypnosis-based intervention to improve well-being during cancer: a comparison between prostate and breast cancer patients
}

C. Grégoire ${ }^{1 *}$, H. Nicolas ${ }^{2}$, I. Bragard ${ }^{1}$, F. Delevallez ${ }^{3}$, I. Merckaert ${ }^{3}$, D. Razavi ${ }^{3}$, D. Waltregny ${ }^{4}$, M.-E. Faymonville ${ }^{5}$ and A. Vanhaudenhuyse ${ }^{5}$

\begin{abstract}
Background: Prostate and breast cancer can have a lot of negative consequences such as fatigue, sleep difficulties and emotional distress, which decrease quality of life. Group interventions showed benefits to emotional distress and fatigue, but most of these studies focus on breast cancer patients. However, it is important to test if an effective intervention for breast cancer patients could also have benefits for prostate cancer patients.

Methods: Our controlled study aimed to compare the efficacy of a self-hypnosis/self-care group intervention to improve emotional distress, sleep difficulties, fatigue and quality of life of breast and prostate cancer patients. 25 men with prostate cancer and 68 women with breast cancer participated and were evaluated before (T0) and after (T1) the intervention.

Results: After the intervention, the breast cancer group showed positive effects for anxiety, depression, fatigue, sleep difficulties, and global health status, whereas there was no effect in the prostate cancer group. We showed that women suffered from higher difficulties prior to the intervention and that their oncological treatments were different in comparison to men.
\end{abstract}

Conclusion: The differences in the efficacy of the intervention could be explained by the baseline differences. As men in our sample reported few distress, fatigue or sleep problems, it is likely that they did not improve on these dimensions.

Trial registration: ClinicalTrials.gov (NCT02569294 and NCT03423927). Retrospectively registered in October 2015 and February 2018 respectively.

Keywords: Breast cancer, Prostate cancer, Group intervention, Hypnosis, Self-care

\section{Background}

Prostate cancer is a major pathology in industrialized countries $[1,2]$ and the second leading cause of death in males $[3,4]$ whereas breast cancer is the most frequently diagnosed cancer and the leading cause of cancer death in females [1]. Survival rates have increased worldwide

\footnotetext{
* Correspondence: ch.gregoire@uliege.be

'Public Health Department and Sensation and Perception Research Group,

GIGA Consciousness, University of Liège, Liège, Belgium

Full list of author information is available at the end of the article
}

[5-7] and more and more patients are living with the consequences of cancer. These two cancers are very common, are gender specific $(100 \%$ of prostate cancer patients being male, about $99 \%$ of breast cancer patients being female), and both impact the sexual organs.

Prostate cancer is frequently diagnosed in later stages because it progresses slowly, leading to delayed treatment [8]. Common treatments for prostate cancer include radical prostatectomy, radiation therapy or brachytherapy, hormonotherapy, or watchful waiting $[7,9,10]$. Treatments for breast cancer include surgery, radiation therapy, chemotherapy, and hormonotherapy [11]. These

(c) The Author(s). 2018 Open Access This article is distributed under the terms of the Creative Commons Attribution 4.0 International License (http://creativecommons.org/licenses/by/4.0/), which permits unrestricted use, distribution, and reproduction in any medium, provided you give appropriate credit to the original author(s) and the source, provide a link to the Creative Commons license, and indicate if changes were made. The Creative Commons Public Domain Dedication waiver (http://creativecommons.org/publicdomain/zero/1.0/) applies to the data made available in this article, unless otherwise stated. 
treatments can have a lot of common negative side effects on patients: pain, physical dysfunction, fatigue, sleep disturbances [12-18], as well as cognitive difficulties [19-24]. These symptoms can contribute to the development of emotional distress, mostly anxiety and depression [13, 25-29], and can postpone or impede patients' return to work [30-32].

In addition, prostate cancer has several specific consequences, such as erectile dysfunction, loss of libido, decreased orgasmic sensation [17, 33-37], or urinary and bowel problems such as incontinence [17, 35, 38, 39]. Breast cancer also has negative impacts on women's femininity as it alters or removes symbols of femininity such as breasts, menstruation, or fertility $[40,41]$. These difficulties encountered by both prostate and breast cancer patients impact a couple's intimacy, communication and sexuality $[12,42-46]$, and can persist for years after the end of treatment [47-51].

In oncology settings, several psychological interventions have been tested in order to improve some of these symptoms. Group interventions such as cognitive-behavioural therapy (CBT) and hypnosis have shown benefits for emotional distress and fatigue [52-59]. However, most of these studies focus on breast cancer patients, and prostate cancer patients are often neglected in psycho-oncological studies [7, 60]. Several systematic reviews investigated non-pharmacological interventions to improve prostate cancer patients' well-being. In their review, Keogh et al. [61] showed that physical activity is helpful to improve general quality of life and to decrease fatigue in such patients. Other systematic reviews have also shown the benefits of physical exercise to improve quality of life [62] and fatigue [63, 64] in these patients. Larkin et al. [64] also showed the efficacy of CBT-based interventions to manage cancer-related fatigue. In their systematic review, Chambers et al. [65] showed the efficacy of CBT-based interventions to improve quality of life, psychological adjustment, and to decrease worry at a 6-month follow-up in prostate cancer patients. They also showed the positive effects of stress-management interventions on quality of life after prostate surgery. Despite these encouraging results, there is a need for more data in order to confirm the efficacy of such interventions.

Given the important negative consequences of prostate and breast cancers, it is important to design interventions to help patients to cope with the effects of treatments $[34,52,66]$.

\section{Objectives}

The aim of our longitudinal study was to test if an effective intervention for breast cancer patients could also have benefits for prostate cancer patients in terms of decreased anxiety, depression, sleep difficulties and fatigue, and increased quality of life.

\section{Methods \\ Participants and design \\ Prostate cancer}

At the end of their treatment, each eligible prostate cancer patient from two oncology services (CHU Liège and CHR Citadelle, Belgium) was directly met or contacted by phone by the experimenter to be informed of the study's aims and design. 152 eligible patients were informed about the study, of which 101 refused to participate. Reasons for refusal were "I am not interested in the proposed intervention", "I have no time for this", "I can manage myself", and "it is too far from home". Five of the 51 remaining patients dropped out of the study because they no longer had the time or suffered from health complications, leaving a final sample of 46 participants. Of these, 25 agreed to participate in the group intervention, and were divided into 5 groups of 4 to 7 patients, whereas 21 did not agree to participate in the intervention because they were not interested or had no time for the intervention. However, they agreed to complete the questionnaires. These patients were included in the control group. Inclusion criteria were $\geq 18$-years-old, ability to read, write and speak French, prostate cancer diagnosis, treatment with surgery and/or radiotherapy. Exclusion criteria were metastases or cancer recurrence at the moment of inclusion, and major cognitive or psychiatric disorder.

\section{Breast cancer}

Breast cancer patients (only from CHU Liège) were directly met or contacted by phone by the experimenter and asked to participate in a group intervention during or after their treatment. We used previously published data of patients included in self-hypnosis/self-care group interventions [52, 67]. In these studies, patients could choose between yoga, cognitive-behavioural therapy, or self-hypnosis/self-care groups. In this study, we focused on patients included in the self-hypnosis/self-care group. Of 426 eligible patients contacted, 114 patients were included in the study. Most common reasons for refusal were "I am not interested in the proposed intervention", "I have no time for this", "I can manage myself" and "it is too far from home". Fifteen patients dropped out of the study, mostly because they no longer had the time, they did not like the intervention, or they developed health complications. Sixty-eight of the 99 remaining patients chose to participate in the hypnosis group and were divided into 13 groups of 3 to 8 participants. Twenty-four patients who did not agree to participate in any group were recruited to form the control group. Inclusion criteria were $\geq 18$-years-old, ability to read, write and speak French, breast cancer diagnosis. Exclusion criteria were metastases or cancer recurrence at the 
moment of inclusion, benefiting from palliative care, and major cognitive or psychiatric disorder.

All participants had to complete an informed consent before starting the study.

The differences in the sample sizes are due to some recruitment difficulties encountered only for the prostate cancer patients. No a priori sample size calculation was performed before the study.

\section{Intervention}

Self-hypnosis/self-care intervention included six 120-min sessions. For the prostate cancer patients, sessions were scheduled on a monthly basis, whereas for the breast cancer patients, they took place every 2 weeks. It means that for prostate cancer patients, the intervention lasted 6 months ( 1 session per month), and that for breast cancer patients it lasted 3 months ( 2 sessions per month). The sessions combined self-hypnosis exercises and self-care techniques and were developed by one of the authors (M-E.F) [68, 69]. This approach fosters engagement in activities, adaptation to the disease, its treatments and side effects, and well-being through discussions and tasks. Tasks are based on self-care techniques and address several topics such as adjusting self-expectation, improving self-esteem, assertiveness, finding one's own personal needs and boundaries, etc. At the end of each session, a 15-min hypnosis exercise was conducted by the therapist and each participant received CDs with the different exercises to encourage at-home training [52, 67, 68]. This intervention aims to help patients to be an actor of their well-being, and we give them practical tasks to reactivate this active role in their improvement after cancer. During the duration of the study, each participant benefited from their usual oncological and medical care, and individual psychological care if needed. Patients from the control groups did not participate in the intervention and only benefited from usual care.

\section{Measures}

Data were collected through questionnaires:

- Medical and sociodemographic data such as age, gender, language, family composition, professional occupation, personal history of cancer and treatment received were collected.

- Hospital Anxiety and Depression Scale (HADS) [70] measures anxiety (7 items) and depression (7 items) during the past week.

- European Organization for Research and Treatment of Cancer - Quality of Life Core Questionnaire-30 (EORTC-QLCQ30) [71] was developed to assess quality of life and incorporates 5 functional scales (physical, role, emotional, cognitive and social functioning) and 9 symptom-related items (fatigue, nausea and vomiting, pain, dyspnea, insomnia, appetite loss, constipation, diarrhea, and financial difficulties). A global health status can also be calculated. In this paper, only the fatigue scale and the global health status are used, as we focus on these variables.

- Insomnia Severity Index (ISI) [72] is a 7-item scale measuring the participant's sleep complaints and the associated distress.

All questionnaires were administrated twice: before (T0) and after (T1) the intervention.

\section{Data analysis}

All statistical analyses were performed using Statistica 13.3 (TIBCO Software Inc.). Baseline (T0) demographic, medical, and psychological data were compared between the treatment and control groups of each population to test initial group equivalency with MANOVA and Chi-square tests. To be considered for data analysis, patients had to complete the two assessments (T0 and T1). Group-by-time changes in depression, anxiety, global health status, fatigue and sleep difficulties were processed using multivariate analysis of variance with repeated measures (MANOVA), followed by post-hoc comparisons (Tukey's HSD test). Effect sizes for standardised differences in means between times of evaluation were calculated using Cohen's d, with interpretation as follows: "small" (<0.20-0.50), "medium" (0.50-0.80), and "large" effect size $(>0.80)$ [73]. All tests were two-tailed and the results were considered to be significant at $p<0.05$. Alpha was set at 0.05 .

\section{Results}

The average attendance rate was 5.3 sessions for prostate cancer patients and 5.4 for breast cancer patients. The demographic and medical data of the sample are displayed in Table 1.

\section{Impact of the intervention on emotional distress, sleep difficulties, fatigue and quality of life in women with breast cancer}

Both the control and the treatment groups were similar at baseline, except for the stage of the disease and the education level (See Table 1). A multivariate analysis of variance of the variables with repeated measures for time of evaluation showed a significant effect of time $(\mathrm{F}(5)=2.59 ; p=0.031)$ and a significant group-by-time interaction effect $(\mathrm{F}(5)=2.76 ; p=0.023)$. Post-hoc comparisons revealed a decrease in anxiety $(p=.000)$, depression $(p=.001)$, fatigue $(p=.003)$ and sleep difficulties $(p=.018)$ and an increase in global health status $(p=.020)$ among women with breast cancer who 
Table 1 Demographic and medical data of the sample

\begin{tabular}{|c|c|c|c|c|c|c|}
\hline & \multicolumn{3}{|c|}{ Breast cancer patients $(N=92)$} & \multicolumn{3}{|c|}{ Prostate cancer patients $(N=46)$} \\
\hline & $\begin{array}{l}\text { Treatment group } \\
(N=68)\end{array}$ & $\begin{array}{l}\text { Control group } \\
(N=24)\end{array}$ & $p$ & $\begin{array}{l}\text { Treatment group } \\
(N=25)\end{array}$ & $\begin{array}{l}\text { Control group } \\
(N=21)\end{array}$ & $p$ \\
\hline \multicolumn{7}{|l|}{ Patient demographics } \\
\hline \multicolumn{7}{|l|}{ Age (years) } \\
\hline Mean (SD) & $54.3(10)$ & $52.5(6.8)$ & .535 & $64.11(5.8)$ & $65.7(4.4)$ & .330 \\
\hline Range & $29-72$ & $39-65$ & & $47-73$ & $58-75$ & \\
\hline \multicolumn{7}{|l|}{ Cultural origin, $N(\%)$} \\
\hline Occidental Europe & $66(97.0)$ & 0 & $N A^{a}$ & $25(100)$ & $21(100)$ & $N A^{a}$ \\
\hline Near and Middle East & $1(1.5)$ & 0 & & 0 & 0 & \\
\hline African & $1(1.5)$ & 0 & & 0 & 0 & \\
\hline Missing data & 0 & $24(100)$ & & 0 & 0 & \\
\hline \multicolumn{7}{|l|}{ Marital status, N (\%) } \\
\hline Single & $5(7.4)$ & $1(4.1)$ & .778 & $1(4.0)$ & 0 & .544 \\
\hline Married/living with partner & $52(76.5)$ & $18(75)$ & & $20(80.0)$ & $16(76.2)$ & \\
\hline Divorced/separated/widowed & $11(16.2)$ & $5(20.8)$ & & $4(16.0)$ & $5(23.8)$ & \\
\hline Missing data & 0 & 0 & & 0 & 0 & \\
\hline \multicolumn{7}{|l|}{ Education level, $N(\%)$} \\
\hline Elementary school or less & 0 & $3(12.5)$ & .001 & $1(4.00)$ & $2(9.5)$ & .557 \\
\hline Lower secondary school & $8(11.8)$ & $7(29.2)$ & & $1(4.00)$ & $4(19.0)$ & \\
\hline Upper secondary school & $21(30.9)$ & $8(33.3)$ & & $7(28.00)$ & $5(23.8)$ & \\
\hline Bachelor's degree & $6(8.8)$ & $4(16.7)$ & & $3(12.00)$ & $1(4.8)$ & \\
\hline Master's degree & $29(42.6)$ & $2(8.3)$ & & $12(48.00)$ & $8(38.1)$ & \\
\hline Post-graduate & $4(5.9)$ & 0 & & $1(4.00)$ & $1(4.8)$ & \\
\hline Missing data & 0 & 0 & & 0 & 0 & \\
\hline \multicolumn{7}{|l|}{ Employment status, N (\%) } \\
\hline Employed part or full time & $9(13.2)$ & $8(33.3)$ & .080 & $8(32.00)$ & $4(19.0)$ & .344 \\
\hline Employed, taken time off & $38(55.9)$ & $12(50)$ & & $2(8.00)$ & $3(14.3)$ & \\
\hline Not employed & $20(29.4)$ & $4(16.7)$ & & $15(60.00)$ & $14(66.7)$ & \\
\hline Missing data & $1(1.5)$ & 0 & & 0 & 0 & \\
\hline \multicolumn{7}{|l|}{ Patient medical history } \\
\hline \multicolumn{7}{|l|}{ Time since diagnosis (months) } \\
\hline Mean (SD) & $7.1(5.1)$ & $5.8(5.0)$ & .368 & $6.16(3.52)$ & $6.00(4.3)$ & .894 \\
\hline Range & $1-27$ & $0.5-19$ & & $1-15$ & $2-22$ & \\
\hline \multicolumn{7}{|l|}{ Cancer stage, N (\%) } \\
\hline 0 & $1(1.5)$ & $3(12.5)$ & & 0 & 0 & \\
\hline 1 & $37(54.4)$ & $13(54.2)$ & & 0 & 0 & \\
\hline 2 & $22(32.4)$ & $3(12.5)$ & .022 & 0 & 0 & \\
\hline 3 & $5(7.4)$ & 0 & & 0 & 0 & \\
\hline Missing data & $3(4.4)$ & $5(20.8)$ & & $25^{\mathrm{b}}$ & $21^{\mathrm{b}}$ & \\
\hline \multicolumn{7}{|l|}{ Surgery, N (\%) } \\
\hline Yes & $68(100)$ & $23(95.8)$ & $N A^{a}$ & $25(100)$ & $21(100)$ & $N A^{a}$ \\
\hline No & 0 & 0 & & 0 & 0 & \\
\hline Missing data & 0 & $1(4.2)$ & & 0 & 0 & \\
\hline
\end{tabular}

Chemotherapy (CT), N (\%) 
Table 1 Demographic and medical data of the sample (Continued)

\begin{tabular}{|c|c|c|c|c|c|c|}
\hline & \multicolumn{3}{|c|}{ Breast cancer patients $(N=92)$} & \multicolumn{3}{|c|}{ Prostate cancer patients $(N=46)$} \\
\hline & $\begin{array}{l}\text { Treatment group } \\
(N=68)\end{array}$ & $\begin{array}{l}\text { Control group } \\
(N=24)\end{array}$ & $p$ & $\begin{array}{l}\text { Treatment group } \\
(N=25)\end{array}$ & $\begin{array}{l}\text { Control group } \\
(N=21)\end{array}$ & $p$ \\
\hline CT completed & $27(39.7)$ & $7(29.2)$ & .727 & 0 & 0 & $\overline{N A^{a}}$ \\
\hline During $C T$ & $20(29.4)$ & $8(33.3)$ & & 0 & 0 & \\
\hline No CT & $21(30.9)$ & $8(33.3)$ & & $25(100)$ & $21(100)$ & \\
\hline Missing data & 0 & $1(4.2)$ & & 0 & 0 & \\
\hline \multicolumn{7}{|c|}{ Radiation therapy (RT), N (\%) } \\
\hline RT completed & $30(44.1)$ & $6(25)$ & .280 & $1(4.0)$ & 0 & .354 \\
\hline During RT & $6(8.8)$ & $2(8.3)$ & & 0 & 0 & \\
\hline Not yet started & $16(23.5)$ & $10(41.7)$ & & 0 & 0 & \\
\hline No RT & $16(23.5)$ & $5(20.8)$ & & $24(96.0)$ & $21(100)$ & \\
\hline Missing data & 0 & $1(4.2)$ & & 0 & 0 & \\
\hline \multicolumn{7}{|c|}{ Hormonal therapy $(\mathrm{HT}), N(\%)$} \\
\hline During HT & $38(55.9)$ & $8(33.3)$ & .209 & $2(8.0)$ & $1(4.8)$ & .658 \\
\hline Not yet started & $23(33.8)$ & $11(45.8)$ & & 0 & 0 & \\
\hline No HT & $7(10.3)$ & $4(16.7)$ & & $23(92.0)$ & $20(95.2)$ & \\
\hline Missing data & 0 & $1(4.2)$ & & 0 & 0 & \\
\hline
\end{tabular}

Bold values indicate significant difference $(p<.05)$

${ }^{a}$ NA (Not applicable) when missing data impeded the analysis, or when the two groups are exactly equivalent $(p=1)$

${ }^{\mathrm{b}}$ All prostate cancer patients were recruited after their surgery and none had metastases

participated in the intervention (see Table 2). The analyses of the effect sizes revealed one medium effect size for the evolution of anxiety before and after the intervention, in the treatment group. All other effect sizes in this group were small.
Impact of the intervention on emotional distress, sleep difficulties, fatigue and quality of life in men with prostate cancer

Both the control and the treatment groups were similar at baseline (See Table 1). Multivariate analysis of variance of

Table 2 Evolution of the data after the intervention in each population

\begin{tabular}{|c|c|c|c|c|c|c|c|c|}
\hline & \multicolumn{8}{|c|}{ Breast cancer group } \\
\hline & \multicolumn{4}{|c|}{ Treatment group ( $N=68$ ) } & \multicolumn{4}{|c|}{ Control group $(\mathrm{N}=24)$} \\
\hline & T0 & $\mathrm{T} 1$ & Evolution (TO-T1) & Effect size & TO & $\mathrm{T} 1$ & Evolution (T0-T1) & Effect size \\
\hline & Mean (SD) & Mean (SD) & $p$ & Cohen's d & Mean (SD) & Mean (SD) & $p$ & Cohen's d \\
\hline HADS - Anxiety & $8.76(4.14)$ & $6.70(3.58)$ & .000 & 0.66 & $7.17(2.96)$ & $7.58(3.40)$ & .916 & -0.13 \\
\hline HADS - Depression & $5.02(3.16)$ & $3.84(3.01)$ & .001 & 0.47 & $4.13(3.72)$ & $4.04(3.00)$ & .999 & 0.04 \\
\hline EORTC - Global Health Status & $59.19(16.23)$ & $65.40(15.83)$ & .020 & -0.38 & $56.94(20.21)$ & $58.33(19.19)$ & .980 & -0.07 \\
\hline EORTC - Fatigue & $52.94(26.05)$ & $44.77(21.72)$ & .003 & 0.41 & $51.85(30.68)$ & $46.30(25.94)$ & .537 & 0.27 \\
\hline \multirow[t]{5}{*}{ Insomnia Severity Index } & $12.65(6.50)$ & $10.60(6.15)$ & .018 & 0.40 & $10.54(6.73)$ & $12.00(5.54)$ & .618 & -0.20 \\
\hline & \multicolumn{8}{|c|}{ Prostate cancer group } \\
\hline & \multicolumn{4}{|c|}{ Treatment group $(\mathrm{N}=25)$} & \multicolumn{4}{|c|}{ Control group $(\mathrm{N}=21)$} \\
\hline & TO & $\mathrm{T} 1$ & Evolution (T0-T1) & Effect size & TO & $\mathrm{T} 1$ & Evolution (T0-T1) & Effect size \\
\hline & Mean (SD) & Mean (SD) & $p$ & Cohen's d & Mean (SD) & Mean (SD) & $p$ & Cohen's d \\
\hline HADS - Anxiety & $6.50(3.06)$ & $4.88(2.98)$ & .085 & 0.50 & $4.76(3.59)$ & $5.71(3.81)$ & .545 & -0.30 \\
\hline HADS - Depression & $3.46(2.47)$ & $3.44(2.89)$ & .992 & 0.01 & $4.19(3.28)$ & $5.05(4.85)$ & .516 & -0.29 \\
\hline EORTC - Global Health Status & $67.67(14.30)$ & $69.33(15.54)$ & .969 & -0.15 & $64.29(20.94)$ & $65.48(25.45)$ & .983 & -0.07 \\
\hline EORTC - Fatigue & $32.44(12.39)$ & $34.22(16.01)$ & .876 & -0.11 & $32.27(27.87)$ & $29.63(29.47)$ & .908 & 0.14 \\
\hline Insomnia Severity Index & $8.04(5.98)$ & $6.92(5.87)$ & .704 & 0.23 & $6.95(5.13)$ & $5.86(4.29)$ & .688 & 0.28 \\
\hline
\end{tabular}


the variables with repeated measures for time of evaluation revealed no significant effect of time or group and no significant interaction effect in men with prostate cancer. Post-hoc comparisons showed no significant evolution of the data in each group after the intervention (see Table 2).

\section{Analysis of the baseline differences between women with breast cancer and men with prostate cancer}

To understand these observed differences between men with prostate cancer and women with breast cancer, we conducted a multivariate analysis of variance on the baseline data from the two treatment groups. A significant effect of sex was shown $(F(5)=3.70 ; p=.004)$. Post-hoc comparisons revealed significant baseline difference between men with prostate cancer and women with breast cancer: women suffered from higher anxiety $(p=.048)$, fatigue $(p=.003)$ and sleep difficulties $(p=.013)$ before the intervention, in comparison to men with prostate cancer. In addition, women were younger than men $(p=.000)$ and the treatment they received differed. All men were off treatment when they were included in self-hypnosis/self-care group (surgery $(N=25)$, radiotherapy $(N=1)$, hormonotherapy $(\mathrm{N}=2)$ ), while the majority of women were still on treatment at the time of the study (chemotherapy $(N=$ $20)$, radiation therapy $(N=6)$ or hormonal therapy $(N=$ $38)$ ). The detailed baseline comparisons of the two treatment groups are displayed in Table 3.

\section{Discussion}

In this study, we compared the efficacy of a self-hypnosis/ self-care group intervention to improve well-being between men with prostate cancer and women with breast cancer. Our results revealed an improvement in anxiety, depression, fatigue, sleep difficulties and global health status in women with breast cancer whereas no significant improvement was shown among men with prostate cancer.

As these results were unexpected, we decided to compare the two treatment groups at baseline. It appeared that the two populations differed at baseline on several variables: women experienced more anxiety, more fatigue, and more severe sleep difficulties. They were also younger than men. These baseline psychological differences could be explained by the fact that most women in our sample endured several treatments (surgery, chemotherapy, radiation therapy and/or hormonal therapy), whereas men mostly received only one surgical intervention. These multimodal treatments could negatively impact the women's well-being, as they are known to cause a lot of negative secondary effects, as described above. These differences in emotional distress observed between men and women were also reported in previous studies on depressive patients [74], cancer patients [68, 75-77], gastroenterology patients $[78,79]$ and the general population [80].

These baseline differences between breast and prostate cancer patients could be a major explanation for our unexpected results observed after the self-hypnosis/self-care intervention. Indeed, as men in our sample did not suffer from high distress, fatigue, sleep problems or low quality of life at baseline, it is likely that their improvement on these variables is low and not significant. On the contrary, women showed high levels of anxiety, fatigue and sleep difficulties, and a lower global health status at baseline.

Our results can also be linked to the difference in the moment at which the intervention took place for men and women. Most men in our sample had already completed their treatment, where the majority of them only received surgery, but a lot of women were still being treated for cancer at the time of the intervention. It is possible that an intervention aimed at improving psychological well-being is more efficient if provided during treatment rather than afterwards, mostly because the treatments are generally highly distressing.

Our results could be explained by the men's tendency to express higher a need for information than for psychological help, and to rarely use available psychological interventions [7, 81, 82]. According to our clinical practice, men with prostate cancer are generally convinced that their surgery will cure them and they discover its negative side effects after several weeks or months. A belief that participating in a psychological intervention will make them less masculine, weaker or more vulnerable is also common. These beliefs could explain the lack of interest in psychological interventions shown by other studies $[7,45,83,84]$. Women with breast cancer, on the contrary, report higher psychological and support needs [7, 45, 81, 82, 85]. As our intervention did not focus on cancer and medical information, but proposed psychological support, sharing of experiences, and learning of self-care techniques and self-hypnosis exercises, it is possible that it did not address men's needs but was more efficient in addressing women's needs. In addition, several studies have highlighted the importance of proposing individualized approaches to help men at a psychological level, as some of them are reluctant to talk about their difficulties in group settings [86, 87].

Finally, our contrasting results could also be linked to the format of the intervention. Women participated in 6 sessions occurring twice a month, while men attended 6 monthly sessions. It is possible that the frequency of the sessions impacts the efficacy of the intervention. Men met less frequently and had to deal with their difficulties on their own for longer periods of time without the support of the group, which could impact the way they implemented the techniques and improved over time. However, we previously showed that monthly self-hypnosis/self-care learning sessions were efficient to 
Table 3 Baseline differences between breast and prostate cancer patients (Treatment groups only)

\begin{tabular}{|c|c|c|c|}
\hline & Breast cancer $(N=68)$ & Prostate cancer $(N=25)$ & Baseline comparison $(p)$ \\
\hline \multicolumn{4}{|l|}{ Patients' demographics } \\
\hline \multicolumn{4}{|c|}{ Age (years) } \\
\hline Mean (SD) & $54.3(10)$ & $64.11(5.8)$ & .000 \\
\hline Range & $29-72$ & $47-73$ & \\
\hline \multicolumn{4}{|c|}{ Cultural origin, $N(\%)$} \\
\hline Occidental Europe & $66(97.0)$ & $25(100)$ & .687 \\
\hline Near and Middle East & $1(1.5)$ & 0 & \\
\hline African & $1(1.5)$ & 0 & \\
\hline Missing data & 0 & 0 & \\
\hline \multicolumn{4}{|c|}{ Marital status, N (\%) } \\
\hline Single & $5(7.4)$ & $1(4.00)$ & .879 \\
\hline Married/living with partner & $52(76.5)$ & $18(72.00)$ & \\
\hline Divorced/separated/widowed & $11(16.2)$ & $4(8.00)$ & \\
\hline Missing data & 0 & $2(8.00)$ & \\
\hline \multicolumn{4}{|c|}{ Education level, N (\%) } \\
\hline Elementary school or less & 0 & $1(4.00)$ & .443 \\
\hline Lower secondary school & $8(11.76)$ & $1(4.00)$ & \\
\hline Upper secondary school & $21(30.88)$ & $7(28.00)$ & \\
\hline Bachelor's degree & $6(8.82)$ & $1(4.00)$ & \\
\hline Master's degree & $29(42.65)$ & $12(48.00)$ & \\
\hline Post-graduate & $4(5.88)$ & $1(4.00)$ & \\
\hline Missing data & 0 & $2(8.00)$ & \\
\hline \multicolumn{4}{|c|}{ Employment status, N (\%) } \\
\hline Employed part or full time & $9(13.2)$ & $8(32.00)$ & .000 \\
\hline Employed, taken time off & $38(55.9)$ & $2(8.00)$ & \\
\hline Not employed & $20(29.4)$ & $15(60.00)$ & \\
\hline Missing data & $1(1.5)$ & & \\
\hline \multicolumn{4}{|l|}{ Patients' medical history } \\
\hline \multicolumn{4}{|c|}{ Time since diagnosis (months) } \\
\hline Mean (SD) & $7.1(5.1)$ & $6.16(3.52)$ & .381 \\
\hline Range & $1-27$ & $1-15$ & \\
\hline \multicolumn{4}{|c|}{ Surgery, N (\%) } \\
\hline Yes & $68(100)$ & $25(100)$ & 1.00 \\
\hline No & 0 & 0 & \\
\hline Missing data & 0 & 0 & \\
\hline \multicolumn{4}{|c|}{ Chemotherapy (CT), N (\%) } \\
\hline CT completed & $27(39.7)$ & 0 & .000 \\
\hline During $C T$ & $20(29.4)$ & 0 & \\
\hline No CT & $21(30.9)$ & $25(100)$ & \\
\hline
\end{tabular}


Table 3 Baseline differences between breast and prostate cancer patients (Treatment groups only) (Continued)

\begin{tabular}{|c|c|c|c|}
\hline & Breast cancer $(N=68)$ & Prostate cancer $(N=25)$ & Baseline comparison $(p)$ \\
\hline Missing data & 0 & 0 & \\
\hline \multicolumn{4}{|c|}{ Radiation therapy (RT), N (\%) } \\
\hline RT completed & $30(44.1)$ & $1(4.00)$ & .000 \\
\hline During RT & $6(8.8)$ & 0 & \\
\hline Not yet started & $16(23.5)$ & 0 & \\
\hline No RT & $16(23.5)$ & $24(96.00)$ & \\
\hline Missing data & 0 & 0 & \\
\hline \multicolumn{4}{|c|}{ Hormonal therapy $(\mathrm{HT}), N(\%)$} \\
\hline During $\mathrm{HT}$ & $38(55.9)$ & $2(8.00)$ & .000 \\
\hline Not yet started & $23(33.8)$ & 0 & \\
\hline No HT & $7(10.3)$ & $23(92.00)$ & \\
\hline Missing data & 0 & 0 & \\
\hline \multicolumn{4}{|l|}{ Patients' psychological state, Mean (SD) } \\
\hline HADS - Anxiety & $8.76(4.14)$ & $6.50(3.06)$ & .048 \\
\hline HADS - Depression & $5.02(3.16)$ & $3.46(2.47)$ & .075 \\
\hline EORTC - Global Health Status & $59.19(16.23)$ & $67.67(14.30)$ & .066 \\
\hline EORTC - Fatigue & $52.94(26.05)$ & $32.44(12.39)$ & .003 \\
\hline Insomnia Severity Index & $12.65(6.50)$ & $8.04(5.98)$ & .013 \\
\hline
\end{tabular}

Bold values indicate significant differences between the two groups

improve the global quality of life in chronic pain patients $[68,69]$.

There are several limitations to our study. First, our sample is quite small, especially for the men with prostate cancer. In addition, no a priori sample size calculation was performed before starting the study. Future studies are needed, with exactly the same design of treatment, to allow a generalisation of our results. The difference in the number of patients included for each cancer could be explained by the results of Clover et al. [88]. They recruited 311 patients with different tumour localisations (including breast and prostate) and showed that the patients currently on treatment were more likely to ask for psychological help than patients not currently on treatment. In addition, women with cancer, especially younger ones, experienced a higher need for psychological help. It is then understandable that our sample includes a lot of younger, in treatment women. Second, women in the treatment group had more severe cancers than women in the control group. This could have impact our results. Finally, as explained above, the intervention was not provided to men and women with the same frequency, which can impact its efficacy, our results and their generalisation.

However, this is one of the first studies comparing the efficacy of a psychological intervention between men with prostate cancer and women with breast cancer, which is of great interest as prostate patients are rarely the focus of psycho-oncological studies $[7,60]$. Therefore, our results highlight the importance of considering the gender of the participants before designing and providing an intervention in oncology settings. Our results also open different research perspectives. First, as already highlighted in the scientific literature [89], it seems essential to design different psychological interventions for cancer patients according to their gender. As our results suggest, an intervention efficient for breast cancer patients could not be pertinent for prostate cancer patients. Several studies suggested that interventions including some physical activity such as fitness training, or concrete stress management techniques, were more accepted by men with cancer and more efficient to improve their well-being [7, 45, 65, 90]. It seems important to assess the influence of the treatment trajectory on the efficacy of this intervention, as the type of treatment and the moment at which the patients participate in the intervention appear to impact our results. Then, future researches should also take into account the treatment journey of their participants before designing an intervention. Indeed, prostate cancer patients in the current study only had surgery, but not other therapy, such as chemotherapy, radiation therapy, and hormonal therapy. Therefore, these patients have probably less negative consequences such as fatigue, sleep difficulties and emotional distress, which may relate to the low efficacy of the intervention for these patients. Different strategies 
could be used to adapt this intervention to men with prostate cancer, such as the inclusion of concrete stress management techniques. It could also be useful to propose this intervention longer after men's treatments, when they are more likely to experience persistent adverse effects of treatments. An individual psychological help could also be suggested before and after the surgery, as well as a few months later, as the group setting could not be the best option for men [86, 87], and the group intervention could be proposed to those who experience more emotional distress. Finally, a more robust design, with an a priori sample size calculation, identical intervention for both groups, and similar treatments in both group could also be used to test the effect of such an intervention on prostate and breast cancer patients.

\section{Conclusion}

In conclusion, our study showed that the intervention combining self-care and self-hypnosis is efficient to improve emotional distress, fatigue, and sleep difficulties in women with breast cancer, but not in men with prostate cancer. These results could be explained by the baseline differences between those two populations, in terms of experienced symptoms, age, and treatments received. Furthermore, the format of the intervention is not exactly the same for the two populations. Finally, men are known to rarely use available psychological interventions, and to express a need for information rather than for psychological help. This could explain why our intervention did not improve their well-being. Further researches are needed in order to assess the efficacy of a hypnosis-based intervention on different populations in oncology settings. Our results highlighted the importance to consider treatments received and gender when designing such interventions.

\section{Abbreviation}

CBT: cognitive-behavioral therapy

\section{Acknowledgements}

This work was supported by the 'Plan National Cancer' of Belgium (Grant numbers 137 and 139), by The King Baudouin Foundation, the National Fund for Scientific Research, the University of Liège and the University Hospital of Liège. We are grateful to all the patients who participated in the study. We also thank Aline Gillet, Florence Lewis, Guy Jerusalem, Philippe Coucke, Gilles Dupuis, and Dominique Lanctôt who helped us to design the study and recruit participants.

\section{Funding}

This study was funded by the King Baudouin Foundation (grant 2016J5120580-205427), the Plan National Cancer of Belgium (Grants Number 137 and 139) and the Belgian National Funds for Scientific Research (FRS-FNRS).

These funds financed the different researchers involved in this study.

\section{Availability of data and materials}

The datasets supporting the conclusions of this article are available upon request. Please contact the corresponding author (ch.gregoire@uliege.be).

\section{Authors' contributions}

CG was responsible for analysis and interpretation of data and drafting the article. AV was responsible for recruitment of patients, acquisition and interpretation of data, and drafting the article. M-EF was responsible for conception and design, acquisition of data, interpretation of data, and drafting the article. IB was responsible for conception and design, recruitment of patients, acquisition and interpretation of data and revising the article. FD, IM and DR were responsible for conception and design. DW and HN were responsible for recruitment of patients and revising the article. All authors read and approved the final manuscript, and agree to be accountable for all aspects of the work in ensuring that questions related to the accuracy or integrity of any part of the work are appropriately investigated and resolved.

\section{Ethics approval and consent to participate}

All procedures performed in this study were in accordance with the ethical standards of the institutional and national research committees and with the 1964 Declaration of Helsinki and its later amendments or comparable ethical standards.

The study was approved by the Ethics Committee of the Faculty of Medicine of the University of Liège, with each participant providing written consent.

\section{Consent for publication}

Not applicable.

\section{Competing interests}

The authors declare that they have no competing interests.

\section{Publisher's Note}

Springer Nature remains neutral with regard to jurisdictional claims in published maps and institutional affiliations.

\section{Author details}

'Public Health Department and Sensation and Perception Research Group, GIGA Consciousness, University of Liège, Liège, Belgium. ${ }^{2}$ Urology Department, CHR Citadelle, Liège, Belgium. ${ }^{3}$ Psychology Department, University, Free University of Brussels, Brussels, Belgium. ${ }^{4}$ Urology Department, University Hospital of Liège, University of Liège, Liège, Belgium. ${ }^{5}$ Algology-Palliative Care Department, University Hospital of Liège, Sensation and Perception Research Group, GIGA Consciousness, University of Liège, Liège, Belgium.

Received: 9 February 2018 Accepted: 18 June 2018

Published online: 22 June 2018

\section{References}

1. Jemal A, Bray F, Center MM, Ferlay J, Ward E, Forman D. Global cancer statistics. CA Cancer J Clin. 2011:61:69-90.

2. Kanso C, Etner J, Debré B, Zerbib M. Cancer de la prostate : aspects médicoéconomiques. Prog En Urol. 2012:85-90.

3. Kibel AS, Ciezki JP, Klein EA, Reddy CA, Lubahn JD, Haslag-Minoff J, et al. Survival among men with clinically localized prostate cancer treated with radical prostatectomy or radiation therapy in the prostate specific antigen era. J Urol. 2012;187:1259-65.

4. Kim HS, Freedland SJ. Androgen deprivation therapy in prostate cancer: anticipated side-effects and their management. Curr Opin Support Palliat Care. 2010:4:147-52.

5. Baade PD, Youlden DR, Krnjacki LJ. International epidemiology of prostate cancer: geographical distribution and secular trends. Mol Nutr Food Res. 2009;53:171-84.

6. DeSantis C, Ma J, Bryan L, Jemal A. Breast cancer statistics, 2013. CA Cancer J Clin. 2014;64:52-62.

7. Visser A. Cancer in a psychosomatic perspective. Somat Psychosom symptoms [internet]. Springer, New York, NY; 2013 [cited 2017 Oct 17]. p. 225-38. Available from: https://link.springer.com/chapter/10. 1007/978-1-4614-7119-6_17.

8. McDowell ME, Occhipinti S, Ferguson M, Dunn J, Chambers SK. Predictors of change in unmet supportive care needs in cancer. Psychooncology. 2010;19:508-16.

9. Holmes JA, Wang AZ, Hoffman KE, Hendrix LH, Rosenman JG, Carpenter WR et al. Is primary prostate cancer treatment influenced by likelihood of 
extraprostatic disease? A surveillance, epidemiology and end results patterns of care study. Int J Radiat Oncol Biol Phys. 2012;84:88-94.

10. Siegel R, DeSantis C, Virgo K, Stein K, Mariotto A, Smith T, et al. Cancer treatment and survivorship statistics, 2012. CA Cancer J Clin. 2012;62: 220-41.

11. Physician Data Query Adult Treatment Editorial Board. Breast Cancer Treatment $\left(\mathrm{PDQ}^{\circledast}\right)$ : Patient Version. PDQ Cancer Inf Summ [Internet]. Bethesda: National Cancer Institute (US); 2002. Available from: http://www. ncbi.nlm.nih.gov/books/NBK65969/

12. Carter N, Bryant-Lukosius D, DiCenso A, Blythe J, Neville AJ. The supportive care needs of men with advanced prostate Cancer. Oncol Nurs Forum. 2011;38:189-98.

13. Die Trill M. Anxiety and sleep disorders in cancer patients. EJC Suppl. 2013;11:216-24.

14. Ewertz $M$, Jensen $A B$. Late effects of breast cancer treatment and potentials for rehabilitation. Acta Oncol Stockh Swed. 2011;50:187-93.

15. Fransson P. Fatigue in prostate cancer patients treated with external beam radiotherapy: a prospective 5-year long-term patient-reported evaluation. J Cancer Res Ther. 2010;6:516-20.

16. Miaskowski C, Paul SM, Cooper BA, Lee K, Dodd M, West C, et al. Predictors of the trajectories of self-reported sleep disturbance in men with prostate cancer during and following radiation therapy. Sleep. 2011:34:171-9.

17. Selli C, Bjartell A, Burgos J, Somerville M, Palacios J-M, Benjamin L, et al. Burden of illness in prostate Cancer patients with a low-to-moderate risk of progression: a one-year, pan-European observational study. Prostate Cancer. 2014;2014:e472949.

18. Weis J, Horneber M. Cancer-Related Fatigue [Internet]. Tarporley: Springer Healthcare Ltd.; 2015 [cited 2016 Dec 2]. Available from: http://link.springer. com/10.1007/978-1-907673-76-4.

19. Gonzalez BD, Jim HSL, Booth-Jones M, Small BJ, Sutton SK, Lin H-Y, et al. Course and predictors of cognitive function in patients with prostate Cancer receiving androgen-deprivation therapy: a controlled comparison. J Clin Oncol. 2015;33:2021-7.

20. Hutchinson AD, Hosking JR, Kichenadasse G, Mattiske JK, Wilson C. Objective and subjective cognitive impairment following chemotherapy for cancer: a systematic review. Cancer Treat Rev. 2012;38:926-34.

21. Jim HSL, Phillips KM, Chait S, Faul LA, Popa MA, Lee Y-H, et al. Meta-analysis of cognitive functioning in breast cancer survivors previously treated with standard-dose chemotherapy. J Clin Oncol Off J Am Soc Clin Oncol. 2012; 30:3578-87.

22. Kesler SR, Adams M, Packer M, Rao V, Henneghan AM, Blayney DW, et al. Disrupted brain network functional dynamics and hyper-correlation of structural and functional connectome topology in patients with breast cancer prior to treatment. Brain Behav. 2017;7 Available from: https://www. ncbi.nlm.nih.gov/pmc/articles/PMC5346525/

23. McGinty HL, Phillips KM, Jim HSL, Cessna JM, Asvat Y, Cases MG, et al. Cognitive functioning in men receiving androgen deprivation therapy for prostate cancer: a systematic review and meta-analysis. Support Care Cancer. 2014;22:2271-80

24. Wu L, Tanenbaum ML, Dijkers MPJM, Amidi A, Hall SJ, Penedo FJ, et al. Cognitive and neurobehavioral symptoms in patients with non-metastatic prostate cancer treated with androgen deprivation therapy or observation: a mixed methods study. Soc Sci Med. 2016;156:80-9.

25. Hernández Blázquez M, Cruzado JA. A longitudinal study on anxiety, depressive and adjustment disorder, suicide ideation and symptoms of emotional distress in patients with cancer undergoing radiotherapy. J Psychosom Res. 2016;87:14-21.

26. Jayadevappa R, Malkowicz SB, Chhatre S, Johnson JC, Gallo JJ. The burden of depression in prostate cancer. Psychooncology. 2012;21:1338-45.

27. Thornton AA, Perez MA, Oh S, Crocitto L. A prospective report of changes in prostate cancer related quality of life after robotic prostatectomy. J Psychosoc Oncol. 2011;29:157-67.

28. Tojal C, Costa R. Depressive symptoms and mental adjustment in women with breast cancer. Psychooncology. 2015;24:1060-5.

29. Watts S, Leydon G, Birch B, Prescott P, Lai L, Eardley S, et al. Depression and anxiety in prostate cancer: a systematic review and meta-analysis of prevalence rates. BMJ Open. 2014;4:e003901.

30. Lindbohm M-L, Kuosma E, Taskila T, Hietanen P, Carlsen K, Gudbergsson S, et al. Cancer as the cause of changes in work situation (a NOCWO study). Psychooncology. 2011;20:805-12.
31. Lindbohm M-L, Taskila T, Kuosma E, Hietanen P, Carlsen K, Gudbergsson S, et al. Work ability of survivors of breast, prostate, and testicular cancer in Nordic countries: a NOCWO study. J Cancer Surviv Res Pract. 2012;6:72-81.

32. Sharp L, Timmons A. Social welfare and legal constraints associated with work among breast and prostate cancer survivors: experiences from Ireland. J Cancer Surviv Res Pract. 2011;5:382-94.

33. Chung E, Brock G. Sexual rehabilitation and Cancer survivorship: a state of art review of current literature and management strategies in male sexual dysfunction among prostate Cancer survivors. J Sex Med. 2013;10:102-11.

34. Donovan KA, Walker LM, Wassersug RJ, Thompson LMA, Robinson JW. Psychological effects of androgen-deprivation therapy on men with prostate cancer and their partners. Cancer. 2015;121:4286-99.

35. Howlett K, Koetters T, Edrington J, West C, Paul S, Lee K, et al. Changes in sexual function on mood and quality of life in patients undergoing radiation therapy for prostate Cancer. Oncol Nurs Forum. 2009;37:E58-66.

36. Smith DP, King MT, Egger S, Berry MP, Stricker PD, Cozzi P, et al. Quality of life three years after diagnosis of localised prostate cancer: population based cohort study. BMJ. 2009;339:b4817.

37. Ussher JM, Perz J, Hawkins Y, Brack M. Evaluating the efficacy of psychosocial interventions for informal carers of cancer patients: a systematic review of the research literature. Health Psychol Rev. 2009;3:85-107.

38. Huang GJ, Sadetsky N, Penson DF. Health related quality of life for men treated for localized prostate cancer with long-term followup. J Urol. 2010;183:2206-12

39. Prabhu V, Sivarajan G, Taksler GB, Laze J, Lepor H. Long-term continence outcomes in men undergoing radical prostatectomy for clinically localized prostate Cancer. Eur Urol. 2014;65:52-7.

40. Karabulut N, Erci B. Sexual desire and satisfaction in sexual life affecting factors in breast cancer survivors after mastectomy. J Psychosoc Oncol. 2009:27:332-43.

41. Park HY, Kim JH, Choi S, Kang E, Oh S, Kim JY, et al. Psychological effects of a cosmetic education programme in patients with breast cancer. J Cancer Care. 2015;24:493-502

42. Manne S, Badr H, Zaider T, Nelson C, Kissane D. Cancer-related communication, relationship intimacy, and psychological distress among couples coping with localized prostate cancer. J Cancer Surviv. 2010;4:74-85.

43. Northouse LL, Katapodi MC, Schafenacker AM, Weiss D. The impact of caregiving on the psychological well-being of family caregivers and Cancer patients. Semin Oncol Nurs. 2012;28:236-45.

44. Goldsmith DJ, Miller GA. Conceptualizing how couples talk about Cancer. Health Commun. 2014;29:51-63.

45. Martin E, Bulsara C, Battaglini C, Hands B, Naumann FL. Breast and prostate cancer survivor responses to group exercise and supportive group psychotherapy. J Psychosoc Oncol. 2015;33:620-34.

46. Mériaux $E$, Joly F. Cancer de la prostate : effets secondaires des traitements sur la masculinité (identité masculine, fertilité, sexualité). Psycho-Oncol. 2017;11:134-7.

47. Davis KM, Kelly SP, Luta G, Tomko C, Miller AB, Taylor KL. The Association of Long-term Treatment-related Side Effects with Cancer-specific and General Quality of life among prostate Cancer survivors. Urology. 2014;84:300-6.

48. Holden AEC, Ramirez AG, Gallion K. Depressive symptoms in Latina breast cancer survivors: a barrier to cancer screening. Health Psychol Off J Div Health Psychol Am Psychol Assoc. 2014;33:242-8.

49. Jones JM, Olson K, Catton P, Catton CN, Fleshner NE, Krzyzanowska MK, et al. Cancer-related fatigue and associated disability in post-treatment cancer survivors. J Cancer Surviv. 2016;10:51-61.

50. Resnick MJ, Koyama T, Fan K-H, Albertsen PC, Goodman M, Hamilton AS, et al. Long-term functional outcomes after treatment for localized prostate Cancer. N Engl J Med. 2013;368:436-45.

51. Taylor KL, Luta G, Miller AB, Church TR, Kelly SP, Muenz LR, et al. Long-term disease-specific functioning among prostate Cancer survivors and noncancer controls in the prostate, lung, colorectal, and ovarian Cancer screening trial. J Clin Oncol. 2012;30:2768-75.

52. Grégoire C, Bragard I, Jerusalem G, Etienne A-M, Coucke P, Dupuis G, et al, Group interventions to reduce emotional distress and fatigue in breast cancer patients: a 9-month follow-up pragmatic trial. Br J Cancer. 2017; 117(10):bjc2017326.

53. Hammond DC. Hypnosis in the treatment of anxiety- and stress-related disorders. Expert Rev Neurother. 2010;10:263-73.

54. Faller $\mathrm{H}$, Schuler M, Richard M, Heckl U, Weis J, Küffner R. Effects of psychooncologic interventions on emotional distress and quality of life in adult 
patients with cancer: systematic review and meta-analysis. J Clin Oncol Off J Am Soc Clin Oncol. 2013;31:782-93.

55. de Vries M, Stiefel F. Psycho-Oncological Interventions and Psychotherapy in the Oncology Setting. In: Goerling U, editor. Psychooncology [Internet]. Berlin Heidelberg: Springer Berlin Heidelberg; 2014. p. 121-135 [cited 2016 Dec 2] Available from: http://link.springer.com/10.1007/978-3-642-40187-9_9.

56. Mitchell SA, Hoffman AJ, Clark JC, DeGennaro RM, Poirier P, Robinson CB, et al. Putting evidence into practice: an update of evidence-based interventions for Cancer-related fatigue during and following treatment. Clin J Oncol Nurs. 2014;18:38-58.

57. Montgomery GH, David D, Kangas M, Green S, Sucala M, Bovbjerg DH, et al. Randomized controlled trial of a cognitive-behavioral therapy plus hypnosis intervention to control fatigue in patients undergoing radiotherapy for breast Cancer. J Clin Oncol. 2014;32:557-63.

58. Cramer H, Lauche R, Paul A, Langhorst J, Kümmel S, Dobos GJ. Hypnosis in breast cancer care: a systematic review of randomized controlled trials. Integr Cancer Ther. 2015;14:5-15.

59. Gudenkauf LM, Antoni MH, Stagl JM, Lechner SC, Jutagir DR, Bouchard $\mathrm{LC}$, et al. Brief cognitive-behavioral and relaxation training interventions for breast cancer: a randomized controlled trial. J Consult Clin Psychol. 2015;83:677-88.

60. Visser A, van Andel G. Psychosocial and educational aspects in prostate cancer patients. Patient Educ Couns. 2003:49:203-6.

61. Keogh JWL, MacLeod RD. Body composition, physical fitness, functional performance, quality of life, and fatigue benefits of exercise for prostate Cancer patients: a systematic review. J Pain Symptom Manag. 2012;43:96-110.

62. Chipperfield K, Brooker J, Fletcher J, Burney S. The impact of physical activity on psychosocial outcomes in men receiving androgen deprivation therapy for prostate cancer: a systematic review. Health Psychol. 2014;33:1288-97.

63. Gardner JR, Livingston PM, Fraser SF. Effects of exercise on treatmentrelated adverse effects for patients with prostate Cancer receiving androgen-deprivation therapy: a systematic review. J Clin Oncol. 2014;32:335-46

64. Larkin D, Lopez V, Aromataris E. Managing cancer-related fatigue in men with prostate cancer: a systematic review of non-pharmacological interventions. J Nurs Pract. 2014;20:549-60.

65. Chambers SK, Pinnock C, Lepore SJ, Hughes S, O'Connell DL. A systematic review of psychosocial interventions for men with prostate cancer and their partners. Patient Educ Couns. 2011;85:e75-88.

66. Newby TA, Graff JN, Ganzini LK, McDonagh MS. Interventions that may reduce depressive symptoms among prostate cancer patients: a systematic review and meta-analysis. Psychooncology. 2015;24:1686-93.

67. Bragard I, Etienne A-M, Faymonville M-E, Coucke P, Lifrange E, Schroeder $H$, et al. A non-randomized comparison study of self-hypnosis, yoga and cognitive behavioral therapy to reduce emotional distress in breast cancer patients. Int J Clin Exp Hypn. 2017 [cited 2017 Jan 13]; Available from: http://orbi.ulg.ac.be/handle/2268/195981.

68. Vanhaudenhuyse A, Gillet A, Malaise N, Salamun I, Barsics C, Grosdent S, et al. Efficacy and cost-effectiveness: a study of different treatment approaches in a tertiary pain Centre. Eur J Pain Lond Engl. 2015;19:1437-46.

69. Vanhaudenhuyse A, Gillet A, Malaise N, Salamun I, Grosdent S, Maquet D, et al. Psychological interventions influence patients' attitudes and beliefs about their chronic pain. J Tradit Complement Med. 2017 [cited 2017 Nov 21]; Available from: http://orbi.ulg.ac.be/handle/2268/207607.

70. Zigmond AS, Snaith RP. The hospital anxiety and depression scale. Acta Psychiatr Scand. 1983;67:361-70.

71. Aaronson NK, Ahmedzai S, Bergman B, Bullinger M, Cull A, Duez NJ, et al. The European Organization for Research and Treatment of Cancer QLQ-C30: a quality-of-life instrument for use in international clinical trials in oncology. J Natl Cancer Inst. 1993;85:365-76.

72. Savard M-H, Savard J, Simard S, Ivers $H$. Empirical validation of the insomnia severity index in cancer patients. Psychooncology. 2005;14:429-41.

73. Cohen J. Statistical power analysis for the behavioral sciences. Massachusetts: Academic Press; 1977.

74. Nolen-Hoeksema S. Gender Differences in Depression. Curr Dir Psychol Sci. 2001;10:173-6.

75. Linden W, Vodermaier A, MacKenzie R, Greig D. Anxiety and depression after cancer diagnosis: prevalence rates by cancer type, gender, and age. J Affect Disord. 2012;141:343-51.

76. Bhattacharjee A, Banerjee A. State and trait anxiety among cancer patients: a comparative analysis. J Psychosoc Res. 2016;11:427-36.
77. Stapleton SJ, Valerio TD, Astroth KS, Woodhouse S. Distress during radiation therapy: assessment among patients with breast or prostate cancer. J Oncol Nurs. 2017;21:93-8.

78. Tang $Y$, Yang $W$, Wang $Y$-L, Lin L. Sex differences in the symptoms and psychological factors that influence quality of life in patients with irritable bowel syndrome. Eur J Gastroenterol Hepatol. 2012;24:702-7.

79. Alosaimi FD, Al-Sultan OA, Alghamdi QA, Almohaimeed IK, Alqannas SI. Gender-specific differences in depression and anxiety symptoms and helpseeking behavior among gastroenterology patients in Riyadh, Saudi Arabia. Neurosci Riyadh Saudi Arab. 2014;19:203-9.

80. McLean CP, Asnaani A, Litz BT, Hofmann SG. Gender differences in anxiety disorders: prevalence, course of illness, comorbidity and burden of illness. J Psychiatr Res. 2011;45:1027-35.

81. Mo PKH, Malik SH, Coulson NS. Gender differences in computer-mediated communication: a systematic literature review of online health-related support groups. Patient Educ Couns. 2009;75:16-24.

82. Nekolaichuk CL, Cumming C, Turner J, Yushchyshyn A, Sela R. Referral patterns and psychosocial distress in cancer patients accessing a psychooncology counseling service. Psychooncology. 2011;20:326-32.

83. Owen JE, Klapow JC, Roth DL, Tucker DC. Use of the internet for information and support: disclosure among persons with breast and prostate cancer. J Behav Med. 2004;27:491-505.

84. Rosenberg JP. Circles in the surf: Australian masculinity, mortality and grief. Crit Public Health. 2009:19:417-26.

85. Sanson-Fisher R, Girgis A, Boyes A, Bonevski B, Burton L, Cook P. The unmet supportive care needs of patients with cancer. Supportive Care Review Group. Cancer. 2000;88:226-37.

86. Halbert CH, Wrenn G, Weathers B, Delmoor E, Ten Have T, Coyne JC. Sociocultural determinants of men's reactions to prostate cancer diagnosis. Psychooncology. 2010;19:553-60.

87. Helgason AR, Dickman PW, Adolfsson J, Steineck G. Emotional isolation: prevalence and the effect on well-being among 50-80-year-old prostate cancer patients. Scand J Urol Nephrol. 2001;35:97-101.

88. Clover KA, Mitchell AJ, Britton B, Carter G. Why do oncology outpatients who report emotional distress decline help? Psychooncology. 2015;24:812-8.

89. Blank TO, Schmidt SD, Vangsness SA, Monteiro AK, Santagata PV. Differences among breast and prostate cancer online support groups. Comput Hum Behav. 2010;26:1400-4.

90. Knols R, Aaronson NK, Uebelhart D, Fransen J, Aufdemkampe G. Physical exercise in cancer patients during and after medical treatment: a systematic review of randomized and controlled clinical trials. J Clin Oncol Off J Am Soc Clin Oncol. 2005;23:3830-42.

Ready to submit your research? Choose BMC and benefit from

- fast, convenient online submission

- thorough peer review by experienced researchers in your field

- rapid publication on acceptance

- support for research data, including large and complex data types

- gold Open Access which fosters wider collaboration and increased citations

- maximum visibility for your research: over $100 \mathrm{M}$ website views per year

At BMC, research is always in progress.

Learn more biomedcentral.com/submissions 